\title{
Online Learning Interaction
}

\author{
Made Hery Santosa \\ mhsantosa@undiksha.ac.id \\ Universitas Pendidikan Ganesha
}

Interactions that occur during the learning process is very important because it is with this information that they get something they want. If an interaction that does not work, then there is no result that follow the interaction process. This short piece of writing intends to describe and discuss a topic on online learning interaction. According to Barab and Thomas (2001), there are two main types of interaction, they are meaningful interaction and meaningless interaction. They function to assist communication of activities and comprehensions.

Chou et al., (2010) mentioned that there are three uses of interaction, they are as follows.

1. Type of interaction: a dialogue between two or more users and also with objects. Examples of this interaction occurs between the user and other users, consumers and researchers, users interact with the system in which the system acts as an instructor, (example: downloading notes and exercises) (Evans \& Sabry, 2003).

2. Interactivity dimension: Interaction examples of interaction between students, between students and instructor, and interaction between students and content (e.g. books and notes) (Muirhead \& Juwah, 2005).

3. Interaction function: the characteristics of the interaction hub or medium used (e.g. email and forum).

At the time when technology is rapidly improving, interactions occur not only between individual and capable individuals alone, but it can happen in the online medium, such as using computers, mobile phones and interactive platforms. In the online learning context, interaction is important for several purposes, like conveying information, giving directions, responding to an activity and other functions. This interaction is also needed for the communication of either learning or other relevant information.

Hasim (2006) proposed an online educational interaction model, highlighting that the online interaction that normally occurs comprises:

1. Teacher-student interaction

2. Student-content interaction

3. Teacher-content interaction 


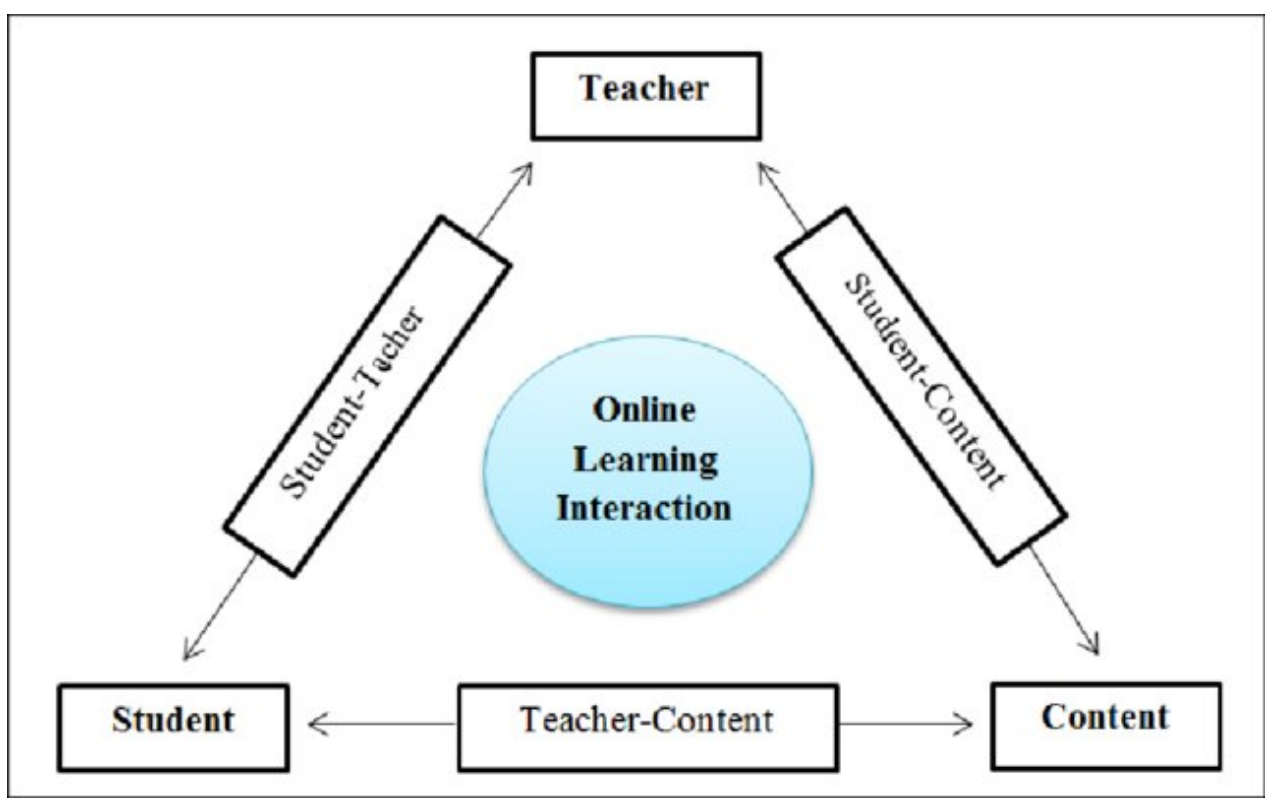

Picture 1. Online Learning Interaction Model (Hashim, 2006)

Stewart et al. (2012; Zucker \& Fisch, 2019) further added the importance of peers in the interaction concept in the online learning context. They believe online educators must fulfil three kinds of interactions in the online learning environment, namely:

1. Student-content interaction, where teachers provide meaningful and active learning activities for students. This normally consists of active learning experiences and reflections. In the online learning context, this interaction type provides learning experiences for students to show their mastery of the topic knowledge in virtual modes.

2. Student-student interaction, where teachers structure the learning community as peers and collaborators. Students learn and support from each other when they interact. In the online learning environment, students are encouraged to experience online learning collaborative works in the live learning platforms.

3. Student-instructor interaction, where teachers create a framework as they will interact with students during the learning activities. In the online learning process, teacher and students may interact in an e-learning platform for the teaching and learning process, like discussion, confirmations, and assessment.

Moore (1989) has supported this importance of peers and stated that interactions in specific types of learning, like collaborative methods requires interactions among students, especially when they aim to convey information or learning content, of when they have difficulties to seek for assistance for solutions.

The three forms of interaction do not happen spontaneously. They require planning, intention, and instructional design. Furthermore, these three types of interaction are not prescriptive, that is they do not require the use of a particular type of learning activity or assessment.

\section{Additional Materials}

To expand your reading, you can read another framework of "Input-process-output model for online interaction learning theory" by Benbunan-Fich, Hiltz, \& Harasim (2004) on "The Online Interaction Learning Model: An Integrated Theoretical Framework for Learning Networks." 
(Link: $\quad$ https://www.taylorfrancis.com/chapters/mono/10.4324/9781410611482-9/onlineinteraction-learning-model-integrated-theoretical-framework-learning-networks-starrroxanne-hiltz-ricki-goldman?context=ubx\&refId=55dccddd-0fb4-4ef6-a814-6ceb4d7e 7155).

\section{References}

Barab, S. A, \& Thomas, M. K. (2001). Online learning: From information dissemination to fostering collaboration. Journal of Interactive Learning Research, 12, 105-143.

Chou, C., Peng, H., \& Chang, C. Y. (2010). The technical framework of interactive functions for course-management systems: Students' perceptions, uses, and evaluations. Computers and Education, 55(3), 1004-1017. doi:10.1016/j.compedu.2010.04.011

Evans, C., \& Sabry, K. (2003). Evaluation of the interactivity of web-based learning systems: Principles and process. Innovations in Education and Teaching International, 40(1), 8999.

Moore, M. G. (1989). Three types of interaction. The American Journal of Distance Education, $3,1-6$.

Muirhead, B., \& Juwah, C. (2005). Insights for teachers and students. International Journal of Instructional Technology and Distance Learning, (2003), 1-145. Retrieved from http://citeseerx.ist.psu.edu/viewdoc/download?doi=10.1.1.100.1936\&rep=rep1\&a mp;type $=$ pdf.

Stewart, A. C., Houghton, S. M., \& Rogers, P. R. (2012). Instructional design, active learning, and student performance: Using a trading room to teach strategy. Journal of Management Education, 36(6), 753-776. https://doi.org/10.1177/1052562912456295.

Zucker, L., \& Fisch, A. (2019). Play and learning with KAHOOT!: Enhancing collaboration and engagement in Grades 9-16 through digital games. Journal of Language and Literacy Education, 15(1).

Please cite this source accordingly using an appropriate reference system and manager. 